\title{
Improving Composite Resin Performance Through Decreasing its Viscosity by Different Methods
}

\author{
Kusai Baroudi* and Rasha Said Mahmoud
}

Department of Restorative Dental Sciences, Al-Farabi College, Riyadh, Saudi Arabia

\begin{abstract}
The aim of this work was to present the different current methods of decreasing viscosity of resin composite materials such as (using flowable composites, lowering the viscosity of the monomer mixture, heating composites and applying sonic vibration) and furnish dentists with a basis that can provide criteria for choosing one or another to suit their therapeutic requirements. The four discussed methods proved that lowering composite viscosity improves its handling and facilitates its application to cavities with complicated forms, decreasing time for procedure and improving marginal adaptation. Other properties improved by decreasing composite resin viscosity were controversial between the four methods and affected by other factors such as composite brand and light cure unit.
\end{abstract}

Keywords: Improving properties, low viscosity, resin composite.

\section{INTRODUCTION}

In the last decade, growing demands by patients for mercury-free, esthetic restorations have markedly increased the use of direct, light-activated resin composites in restorative dentistry [1].

A major drawback of current composite-based resins is that they contract or shrink during conversion from monomer to polymer. The resin matrix of all composite- based resin restorative materials shrinks volumetrically approximately 10 percent during polymerization [2]. This polymerization shrinkage stresses the adhesive between the tooth and the restorative material, frequently resulting in failure of this bond and marginal infiltration [3].

These problems have activated producers to find solutions and to make either the material or the technique easier to apply and faster to use. The effect of lowering viscosity to improve adaptation of the composite and to improve ease of placement has been shown to be important [4]

Compared with conventional composite resins, these new composite resins with low viscosity boost few advantages: easily applicable to cavities with complicated forms, time required for the filling procedure is short, and excellent in cavity sealing $[5,6]$.

\subsection{Flowable Composites}

One of the methods used for decreasing composite viscosity is the development of flowable resin composites. Flowable resin composites; being less viscous material improve the wettability by flowing onto all prepared surfaces creating an intimate union with the micro structural defects in the floor and the walls of the cavity preparation. Moreover, they act as a flexible intermediate layer that helps to

*Address correspondence to this author at the Department of Restorative Dental Sciences, Al-Farabi College, Riyadh 11691, P.O. Box 85184, Kingdom of Saudi Arabia; Tel: 00966-12273151; Fax: +966 1 2324580;

E-mail: d_kusai@yahoo.co.uk relieve stresses during polymerization shrinkage of the restorative resin. These characteristics and a syringe delivery system make them an ideal choice for the use as a liner [7, 8]. Flowable composites achieve their lower viscosity primarily by a reduction in reinforcing filler content and changes in the matrix chemistry $[9,10]$. However, it is well known that a decrease in filler content will affect various properties of a hardened composite resin, such as the mechanical strength and curing shrinkage [11]. Against this background, it is important to investigate how to lower the viscosity of a composite resin without decreasing its filler content [12]. Thus far, the most uncomplicated method of decreasing the viscosity of composites is to lower the viscosity of the monomer mixture itself.

\subsection{Lowering Monomer Viscosity}

The base monomer most widely used commercially is BisGMA (bisphenol A diglycidil dimethacrylate; $\mathrm{MW}=512$ $\mathrm{g} / \mathrm{mol}$. Despite its high intrinsic reactivity, the presence of hydroxyl groups on the backbone and the $\pi-\pi$ interactions given by the aromatic rings increase the initial viscosity $(\eta=1,200 \mathrm{~Pa})$ to a point that the homopolymer typically does not reach high conversion [13]. For that reason, and also to improve handling characteristics and allow incorporation of higher inorganic filler contents, BisGMA is usually combined with low free viscosity monomers like TEGDMA (triethylene glycol dimethacrylate; $\mathrm{MW}=286 \mathrm{~g} / \mathrm{mol}, \eta=0.01$ $\mathrm{Pa}$. However, addition of TEGDMA increases water sorption and polymerization shrinkage $[14,15]$. To overcome these effects, studies have been directed toward developing low viscosity, more hydrophobic Bis-GMA analogs such as the hydroxyl-free propoxylated Bis-GMA (CH3Bis-GMA) and propoxylated fluorinated Bis-GMA (CF3Bis-GMA), as replacements for TEGDMA in Bis-GMA mixtures [16, 17]. Also, in an attempt to improve properties of methacrylate resins, aldehyde-propanal (propionaldehyde) or diketonediacetyl (2,3-butanedione) have been added as potential crosslinking agents with appreciable success $[18,19]$. 


\subsection{Heating Composite}

Many polymer resins exhibit lower viscosity when they are heated. The theoretical basis for this behavior is that thermal energy forces the composite monomers or oligomers further apart, allowing them to slide by each other more readily. Studies have shown that heating general polymers and resin composites lowers viscosity and thereby improves adaptation [20].

\subsection{Sonic Vibration}

A new method of restoration relies on more sophisticated instruments that condense the material by vibration. Such devices have been created by several producers and operate according to the same principle: sonic vibration .The principle of this technique assumes that vibration lowers the viscosity of the resin, allowing the material to flow and easily adapt to the cavity walls without air pores, in a similar way as a flowable composite. Thus, a condensable material with increased viscosity can be used similar to a flowable composite, without the disadvantage of high polymerization shrinkage and poor mechanical properties [21].

Our review aimed to disclose that if decreasing viscosity of resin composites through the four mentioned methods has an impact on the performance of the restoration by improving its properties.

\section{MATERIALS AND METHODS}

With the help of currently available literature, this paper attempted to point out four methods used for decreasing composite viscosity and their ability to improve its properties. The electronic database PubMed was searched for scientific articles on the four methods. The search was carried out between 2004 and 2014 to represent the latest developments in the last 10 years.

The search words low viscosity, flowable composite, low viscosity monomers, preheated composites and sonic vibration were used. The search was done for each method separately. Total 59 papers were selected out of 70 papers. The selection was done on the basis of papers that correlate the selected method of decreasing viscosity to its effect on the performance of restoration. The rejected papers discussed other aspects as well which are not related to the scope of the review. The results of selected studies were presented in Tables $\mathbf{1}, \mathbf{2}, \mathbf{3}$, and $\mathbf{4}$. The papers were listed in the tables with ascending arrangement according to the year of publication.

\section{DISCUSSION}

Today, improvements in formulations, optimization of properties and the development of new techniques for placement have made the restoration of direct composite more reliable and predictable. Producers tried to decrease the viscosity of dental composite to make either the material or the technique easier to apply and faster to use. Several solutions have been proposed to decrease composite viscosity.

\subsection{Flowable Composites}

The first way discussed in this review was; using flowable composite Table (1) [22-35]. The use of flowable resin composite as an intermediate layer liner when studied for occlusal, cervical and proximal restorations, showed different results. Some authors found this application improves the marginal seal, Olmez et al., 2004 [22] concluded that; a composite lining in a Class II resin composite with margins below the cemento enamel junction may reduce marginal microleakage and voids in the interface and the total number of voids in the restoration. Sadeghi et al., 2009 [28] also concluded that; a layer of flowable materials at the gingival floor of Class II composite restorations may be recommended to improve the marginal seal of a restoration. The same idea was supported by Simi et al., 2011 [32] who concluded that; both resin-modified and flowable composite liners under nano composite restorations result in comparable reduction of micro leakage.

In contrast; others failed to show any benefits from using flowable composite as a liner. Tredwin et al., 2004 [23] found use of a flowable composite liner against cementum/dentin was associated with increased micro leakage. Lindberg et al., 2005 [24] and Pecie et al., 2013 [35] found that the use of flowable resin composite did not rinfluence the interfacial adaptation. Van dijken et al., 2011 [31] also concluded that; the use of flowable resin composite as an intermediate layer did not result in improved effectiveness of the Class II restorations.

Using liner under occlusal restoration was studied by Efes et al., 2006 [26] who found that; the clinical performance of occlusal restorations did not benefit from the additional use of the flowable composite.

Using flowable composite as a liner in class $\mathrm{V}$ cavities was studied by Arslan et al., 2013 [34] who stated that; micro leakage is not affected by the application of either conventional or new-generation flowable composite resin as an intermediate material between composite resin and dental substrates. Also, Loguercio et al., 2005 [25] stated that; the use of Filtek Flow as a liner under Filtek Z250 restorations did not improve the clinical performance of class $\mathrm{V}$ restorations after 6 and 12 months of evaluation.

When performance of flowable resin materials in noncarious cervical lesions was studied; acceptable clinical performance (except for the retention rates of the Dyract Flow restorations) in non-carious cervical lesions was stated by Celik et al., 2007 [27] with no significant differences were found between the flowable and microhybrid resin materials $(\mathrm{p}>0.05)$. The same conclusion was recorded by Kubo et al., 2010 [29] who found that: both types of resin flowable and hybrid resin composite in conjunction with S3 Bond demonstrated an acceptable clinical performance up to 3 years when applied to non-carious cervical lesions with no significant differences.

Clinical efficacy of two flowable composite resins used to restore occlusal caries lesions was investigated by Gallo et al., 2010 [30] who observed that marginal discoloration, polishability and marginal adaptation significantly worsened at 36 months and he suggested that they should be limited to small restorations such as preventive resin restorations having isthmus widths of one-quarter or less of intercuspal distance. Bonilla et al., 2012 [33] reached the same conclusion when they studied placing flowable composite as minimally invasive occlusal restorations. Their results showed that a 
Table 1. Studies that investigated micro leakage and marginal adaptation of flowable composites.

\begin{tabular}{|c|c|c|c|}
\hline Olmez, A [22] 2004 & $\begin{array}{l}\text { Class II composite restorations with } \\
\text { the margins below the } \\
\text { cemento-enamel junction as a liner }\end{array}$ & $\begin{array}{l}\text { Marginal microleakage and } \\
\text { internal voids }\end{array}$ & $\begin{array}{l}\text { The use of flowable resin composites provided a reduction in } \\
\text { marginal microleakage and a reduction in some parts of the } \\
\text { internal voids or total voids }\end{array}$ \\
\hline $\begin{array}{l}\text { Tredwin, C.J [23] } \\
\mathbf{2 0 0 4}\end{array}$ & Class II cavities as aliner & Micro leakage & $\begin{array}{l}\text { Leakage data do not support the use of flowable resin } \\
\text { composite linings in Class II resin composite restorations }\end{array}$ \\
\hline $\begin{array}{l}\text { Loguercio, A. D [25] } \\
\qquad 2005\end{array}$ & Class $\mathrm{V}$ as a liner & $\begin{array}{l}\text { Clinical performance over } 1 \\
\text { year }\end{array}$ & $\begin{array}{l}\text { The use of Filtek Flow as a liner under Filtek Z250 restora- } \\
\text { tions did not improve the clinical performance of class V } \\
\text { restorations after } 6 \text { and } 12 \text { months of evaluation. }\end{array}$ \\
\hline $\begin{array}{l}\text { Sadeghi, M }[28] \\
\quad 2009\end{array}$ & Class II as gingival liner & Micro leakage & $\begin{array}{l}\text { The groups utilizing flowable liners had significantly less } \\
\text { microleakage with no significant difference between utilizing } \\
\text { flowable composite or flowable compomer }\end{array}$ \\
\hline $\begin{array}{l}\text { Kubo, } S[29] \\
2010\end{array}$ & Non-carious cervical lesions & $\begin{array}{l}\text { Three-year clinical } \\
\text { performance }\end{array}$ & $\begin{array}{l}\text { There were no significant differences in the clinical perform- } \\
\text { ances between the hybrid and the flowable composite for each } \\
\text { variable acceptable clinical performance up to } 3 \text { years. }\end{array}$ \\
\hline Gallo, J.R [30] 2010 & Occlusal as a restoration & Clinical efficacy & $\begin{array}{c}\text { Marginal discoloration and marginal adaptation significantly } \\
\text { worsened at } 36 \text { months. }\end{array}$ \\
\hline $\begin{array}{l}\text { Bonilla, E.D [33] } \\
\text { 2012. }\end{array}$ & $\begin{array}{l}\text { Minimally invasive occlusal } \\
\text { restorations. }\end{array}$ & Micro leakage & $\begin{array}{l}\text { Using flowable composite in minimally invasive } \\
\text { occlusal restorations might result in undue restoration pitting } \\
\text { or degradation. }\end{array}$ \\
\hline Arslan, S [34] 2013 & $\begin{array}{l}\text { Class V restorations as } \\
\text { intermediate material }\end{array}$ & Micro leakage & $\begin{array}{c}\text { Micro leakage is not affected by the application of either } \\
\text { conventional or new-generation flowable composite resin as } \\
\text { an intermediate material between composite resin } \\
\text { and dental substrates }\end{array}$ \\
\hline Pecie, R [35] 2013 & Class II as a liner & Marginal adaptation & $\begin{array}{l}\text { The application of flowable composite as a liner may not } \\
\text { improve marginal adaptation and is product dependent. }\end{array}$ \\
\hline
\end{tabular}

conventional microhybrid composite material, leaked significantly less than all the flowable composite groups. Tiny microscopic bubbles were seen within many of the flowable composite specimens, as were a few voids.

\subsection{Lowering Monomer Viscosity}

The second discussed way for decreasing composite resin viscosity was decreasing monomer mixture viscosity (Table 2) [36-42]. Most of the composite resins widely used in restorative dentistry contain the highly viscous monomer 2,2-bis [4- (2-hydroxy-3-methacryloxyprop-1-oxy) phenyl] propane (Bis-GMA) and low-viscosity monomers, used as diluents, in order to achieve high filler loading. In particular, triethylene glycol dimethacrylate (TEGDMA) has been extensively used for such purpose.

Studies have been directed toward developing low viscosity, hydroxyl free, more hydrophobic Bis-GMA analogs. Okamura et al., 2006 [37] evaluated the dental application possibility of producing, experimental composite resins of low-viscosity monomer mixtures using low-viscosity 
Table 2. Studies that investigated the decreasing viscosity through monomer changes.

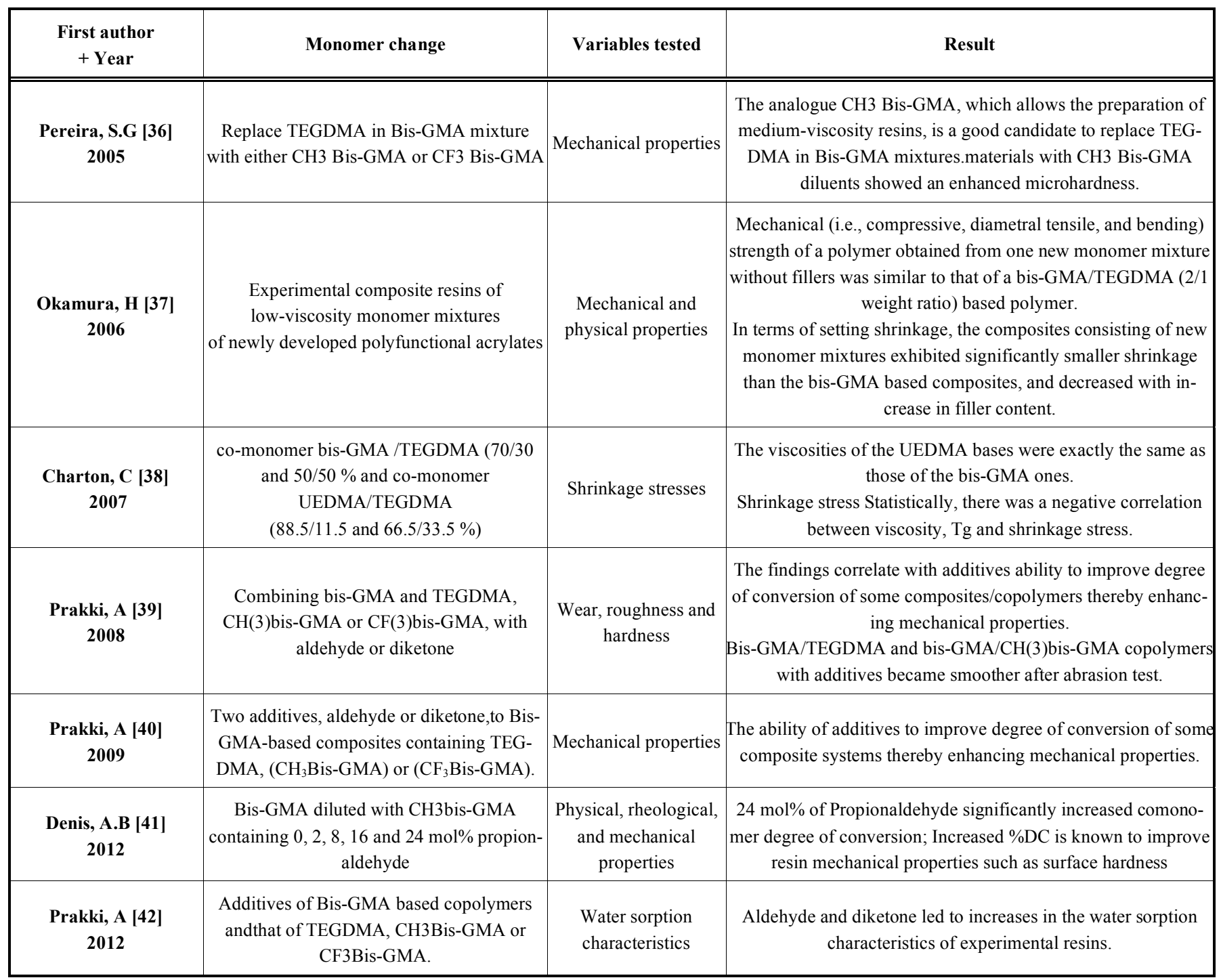

monomer mixtures of newly developed polyfunctional acrylates. The viscosity of composite pastes with high filler content was markedly lower than that of Bis-GMA based composites. Compressive strengths of composite resins produced using the new monomer mixtures were similar to that of composite resin produced using Bis-GMA monomer mixture. In terms of setting shrinkage, the composites consisting of new monomer mixtures exhibited significantly smaller shrinkage than the Bis-GMA based composites, and decreased with increase in filler content. Such small setting shrinkage might be attributed to the relatively large volume of polyfunctional monomers and the relatively small intermolecular distance.

Pereira et al., 2005 [36] investigated the influence of new diluent agents, diluent ratio and filler content, on relevant mechanical properties of several novel composite resins containing Bis-GMA as resin matrices, and to compare these with the properties of composites based on TEGDMA, a conventionally used diluent. Two Bis-GMA analogues were synthesized combining three monomer mixtures (BisGMA/TEGDMA, Bis-GMA/CH3 Bis-GMA and Bis-
GMA/CF3 Bis-GMA). Materials with CH3 Bis-GMA showed an enhanced micro hardness VHN. Mean Flexural strength (FS) was higher for matrices containing TEGDMA. Overall, dilution favored FS and VHN but not modulus of elasticity ME.

Adding additives to the Bis-GMA monomer that decreased viscosity was studied by Prakki et al., 2009 [40] where two additives, propionaldehyde/aldehyde or 2,3butanedione/diketone, was added. Degree of conversion (DC $\%$, flexural strength (FS), modulus of elasticity (E), modulus of resilience (R) and diametral tensile strength (DTS) were determined. Incorporation of additives led to an increase in DC\%, FS and $\mathrm{E}$ for Bis-GMA/TEGDMA and Bis-GMA/CH (3) Bis-GMA systems. R-values for all systems were unaffected by addition of additives. They had no significant effect on DC\% or mechanical properties of BisGMA/CF (3) Bis-GMA. Same conclusion reached by the same authors [39] when they tested wear, roughness and hardness as affected by the two additives and concluded that; incorporation of additives led to improved $\mathrm{W}$ and $\mathrm{H}$ values for bis-GMA/TEGDMA and bis-GMA/ $\mathrm{CH}_{3}$ bis-GMA 
Table 3. Studies that investigated the effect of preheating resin composites on micro leakage in class II and V, degree of conversion, mechanical properties, polymerization shrinkage, hardness and marginal adaptation.

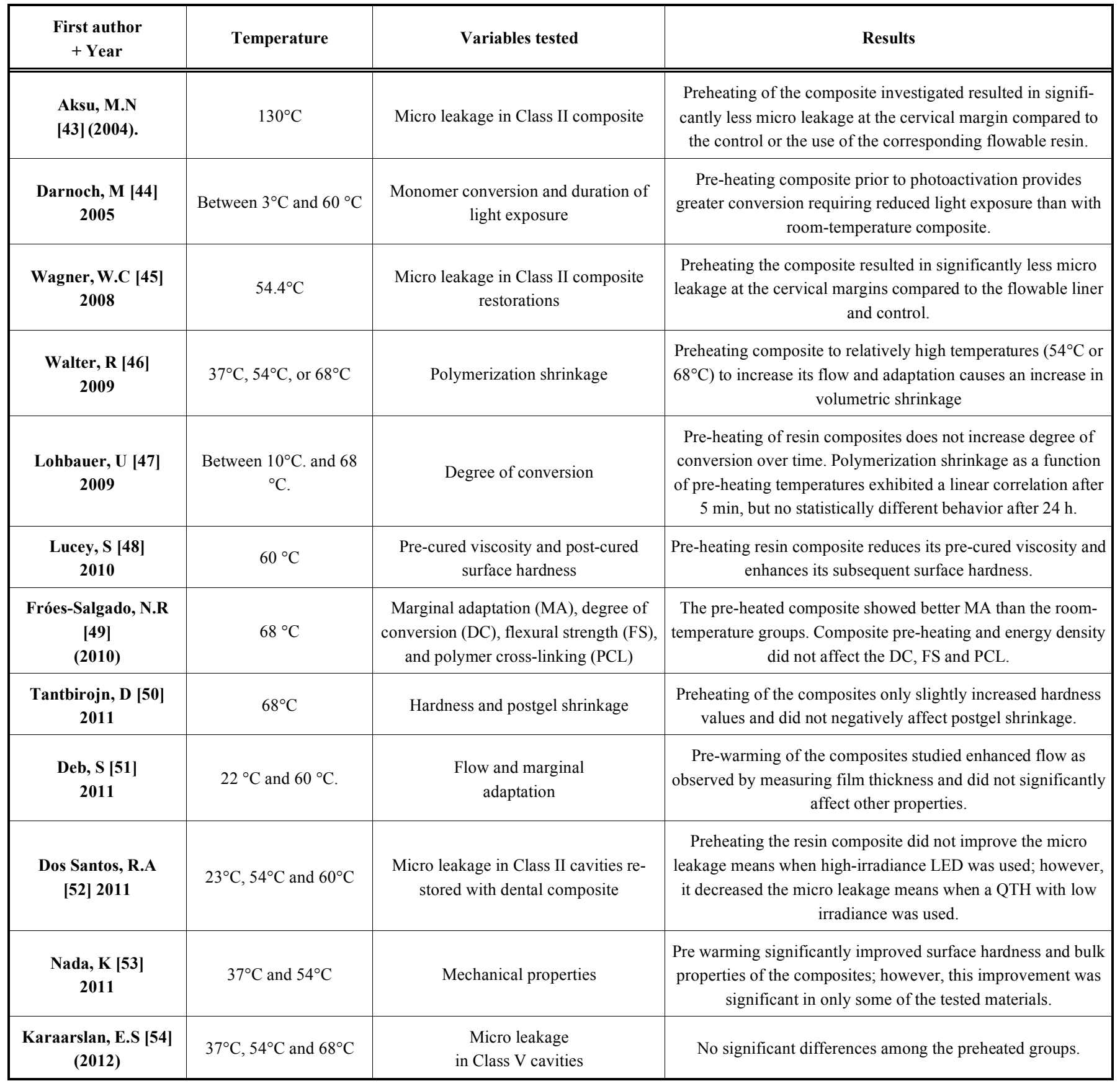

systems, additives had no significant effect on the $\mathrm{W}$ and $\mathrm{H}$ changes of bis-GMA/ $\mathrm{CF}_{3}$ bis-GMA, also concluded that; BisGMA/TEGDMA, bis-GMA/ $\mathrm{CH}_{3}$ bis-GMA copolymers with additives became smoother after abrasion test.

The same conclusions was reached by Denis et al., 2012 [41] who evaluated the physical, rheological, and mechanical properties of Bis-GMA diluted with $\mathrm{CH} 3$ bis-GMA containing $0,2,8,16$ and $24 \mathrm{~mol} \%$ propionaldehyde. It has been reported that the viscosity of propionaldehyde is $3 \times 10-5$ Pa.s and its incorporation into comonomers significantly lowers the viscosity of CH3bis-GMA-based resins. The present findings revealed that the incorporation of propionalde- hyde into the experimental resins gradually increased \% DC as the mol \% of the additive increased.

Prakki et al., 2012 [42] tested the effect of additives on the water sorption characteristics of Bis-GMA based copolymers and composites containing TEGDMA, CH3BisGMA or CF3Bis-GMA. Water sorption and desorption were evaluated in a desorption-sorption-desorption cycle. Water uptake (\%WU), water desorption (\%WD), equilibrium solubility $\left(\mathrm{ES} ; \mu \mathrm{g} / \mathrm{mm}^{3}\right)$, swelling (f) and volume increase $(\% \mathrm{~V})$ were calculated using appropriate equations. All resins with additives had increased \%WU and ES. TEGDMA-containing systems presented higher \%WU, \%WD, ES, f and \%V 
Table 4. Studies that investigated the effect of sonic vibration on depth of cure, marginal micro leakage, and mechanical performance.

\begin{tabular}{|c|c|c|c|}
\hline $\begin{array}{l}\text { First author } \\
\quad+\text { Year }\end{array}$ & Vibration device & Variables tested & Conclusion \\
\hline $\begin{array}{l}\text { Yapp, R [55] } \\
2011\end{array}$ & Sonic fill & $\begin{array}{l}\text { Depth of cure of several composite } \\
\text { restorative materials }\end{array}$ & $\begin{array}{l}\text { Sonicfill is adequately cured at the maximum recommended } \\
\text { depth when cured with the Demi curing light }\end{array}$ \\
\hline $\begin{array}{l}\text { Eunice, C [56] } \\
\quad 2012\end{array}$ & $\begin{array}{l}\text { SonicFillTM } \\
\text { (Kerr/Kavo }\end{array}$ & Marginal micro leakage in class $\mathrm{v}$ & $\begin{array}{l}\text { SonicFill TM only has the advantage of better clinical } \\
\text { handling, reducing labour time no influence in } \\
\text { con-cerning microleakage }\end{array}$ \\
\hline $\begin{array}{l}\text { Ilie, } N \text { [57] } \\
\quad 2013\end{array}$ & SonicFill, Kerr; & $\begin{array}{l}\text { Mechanical performance of seven } \\
\text { bulk-fill RBCs }\end{array}$ & $\begin{array}{l}\text { The significant highest flexural strengths were measured for } \\
\text { SonicFill }\end{array}$ \\
\hline $\begin{array}{l}\text { Poggio, C }[58] \\
2013\end{array}$ & SonicFill (Kerr) & $\begin{array}{l}\text { microleakage in "deep" Class II composite } \\
\text { restorations with gingival cavosurface } \\
\text { margin below the CEJ }\end{array}$ & $\begin{array}{l}\text { Significant prevalence of Score } 0 \text { (no dye penetration) was } \\
\text { reported both for Groups } 4 \text { (SonicFill) and } 5 \text { (Grandio), }\end{array}$ \\
\hline
\end{tabular}

values, followed by resins based on CH3Bis-GMA and CF3Bis-GMA. Aldehyde and diketone led to increases in the water sorption characteristics of experimental resins.

Charton et al., 2007 [38] showed different results about monomer viscosity when he investigated Influence of glass transition temperature $\mathrm{Tg}$, viscosity and chemical structure of monomers on shrinkage stress in light-cured dimethacrylate-based dental resins. The large differences in stress values for the pairs with the same viscosity, showed that; it is not the viscosity in itself which has a dominating influence on stresses (via the DC). They concluded that; whatever the viscosity, the UEDMA-based matrices developed higher shrinkage stresses than the Bis-GMA homologues.

\subsection{Heating Composite}

The third discussed method in this review was preheating composite before photo activation (Table 3) [43-54]. Chair side warming of composite resins before photo polymerization is one of the recent trends in their application.

Daronch et al., 2005 [44] concluded that; pre-heating composite prior to photo activation provides greater conversion requiring reduced light exposure than with roomtemperature composite. Different results were reached by Lohbauer et al., 2009 [47] and Fróes-Salgado et al., 2010 [49].

The first one concluded that; pre-heating of resin composites does not increase degree of conversion over time. It can be clinically beneficial, due to a superior marginal adaptation. The second one reached the same conclusion when he studied the effect of composite pre-polymerization temperature and energy density on the marginal adaptation (MA), degree of conversion (DC), flexural strength (FS), and polymer cross-linking (PCL) of a resin composite. He concluded that: Pre-heating the composite prior to light polymerization did not alter the mechanical properties and monomer conversion of the composite, but provided enhanced composite adaptation to cavity walls.
Deb et al., 2011 [51] evaluated if pre warming of composites would influence the flow and enhance marginal adaptation and, he stated that; pre-warming of the composites studied enhanced flow as observed by measuring film thickness and did not significantly affect other properties.

Micro leakage as affected by preheating was discussed with two different points of view. The first one correlated composite preheating to the reduction in micro leakage in class II composite. Wagner et al., 200845 and Aksu et al., 2004 [43] supported this view, the first one compared micro leakage in Class II composite restorations prepared using: preheated resin composite, and unheated composite and found no statistical differences among materials at the occlusal margin. However, at the cervical margin, the preheated samples showed statistically lower micro leakage than the controls and all other treatments. The second study also stated that; preheating of the composite investigated resulted in significantly less micro leakage at the cervical margin compared to the control or the use of the corresponding flowable resin. The other point of view by Dos Santos et al., 2011 [52] who found that; the decrease in micro leakage in Class II cavities restored with preheated dental composite happened when a QTH with low irradiance was used but, not improved when high-irradiance LED was used. Karaarslan et al., 2012 [54] also tested the micro leakage as affected by preheating composite and found no significant differences among the preheated groups.

Mechanical properties and polymerization shrinkage for preheated composite were tested with varied results. Walter et al., 2009 [46] studied whether temperature affects the polymerization shrinkage of composite resin and concluded that: Preheating composite to relatively high temperature $54 \mathrm{c}$ or $88 \mathrm{c}$ to increase its flow and adaptation causes an increase in volumetric shrinkage. This result was opposed by Tantbirojn et al., 2011 [50] who evaluated the effect of composite preheating and light-curing duration on hardness and postgel shrinkage and stated that; preheating of the composites only slightly increased hardness values and did not negatively affect postgel shrinkage. 
Lucey et al., 2010 [48] tested the pre-cured viscosity and post-cured surface hardness for the preheated composite and stated that; pre-heating resin composite reduces its pre-cured viscosity and enhances its subsequent surface hardness. This conclusion was supported by Nada et al., 2011 [53] who found that the effect of pre polymerization warming on composites' mechanical properties, is material dependent; pre warming significantly improved surface hardness and bulk properties of the composites; however, this improvement was significant in only some of the tested materials.

\subsection{Sonic Vibration}

The last discussed method was sonic vibration (Table 4) [55-59]. Up to now, little independent studies assessed the vibration technique, also some data offered by the producers of such devices being available.

Microleakage was investigated by two studies the first by Eunice et al., 2012 [56] who stated that; the sonic system has no effect concerning microleakage. The second study by Poggio et al., 2013 [58] on contrast proved that sonic fill composites showed the lowest microleakage values when compared with other groups tested micro leakage in "deep" Class II composite restorations with gingival cavosurface margin below the CEJ.

Alrahlah et al., 2014 [59] studied post-cure depth of cure of bulk fill resin composites through using Vickers hardness profiles (VHN), they stated that SonicFill exhibited the highest VHN, also sonic fill and Tetric EvoCeram bulk fill had the greatest depth of cure among the composites examined. Ilie et al., 2013 [57] also studied the mechanical performance of seven bulk-fill RBCs and he stated that; the significant highest flexural strengths were measured for SonicFill.

Yapp et al., 2011 [55] found that; sonic fill adequately cured at the maximum recommended depth when cured with Demi curing light set to yield a saw tooth when used according to manufacturer's direction for use.

\section{CONCLUSION}

No benefits from the additional use of the flowable composite as a liner for interfacial adaptation and micro leakage. Lowering monomer viscosity by replacing TEGDMA in BisGMA/diluent mixtures with $\mathrm{CH} 3$ Bis-GMA, or CF3 BisGMA consequently improves degree of conversion DC, polymerization shrinkage (PS) and handling properties. Additives are able to improve degree of conversion of some composite systems thereby enhancing mechanical properties. Preheating composite reduces viscosity and increases flowability, which facilitates better adaptation to cavity walls; this reduces micro leakage and results in superior marginal adaptation. Condensation of composite resins can be faster achieved by using vibrating instruments. Vibration decreases the viscosity of the material and facilitates its flow within the preparation irregularities with better adaptation of the material to the cavity walls.

\section{CONFLICT OF INTEREST}

The authors confirm that this article content has no conflict of interest.

\section{ACKNOWLEDGEMENTS}

Declared none.

\section{REFERENCES}

[1] Ilie N, Jelen E, Clementino-Luedemann T, Hickel R. Low shrinkage composite for dental application. Dent Mater 2007; 26:149-55.

[2] Van Meerbeek B, Perdigao J, Lambrechts P, Vanherle G. The clinical performance of adhesives. J Dent 1998; 26:1-20.

[3] Browne RM, Tobias RS. Microbial microleakage and pulpal inflammation: a review. Endod Dent Traumatol 1986; 2:177-83.

[4] Clelland NL, Pagnotto MP, Kerby RE, Seghi RR. Relative wear of flowable and highly filled composite. J Prosthet Dent 2005; 93:153-7.

[5] Yazici AR, Ozgunaltay G, Dayangac B. The effect of different types of flowable restorative resins on microleakage of Class $\mathrm{V}$ cavities. Oper Dent 2003; 28: 773-8.

[6] Neme AM, Maxson BB, Pink FE, Aksu MN. Microleakage of Class II packable resin composites lined with flowables: An in vitro study. Oper Dent 2002; 27 : 600-5.

[7] Payne JH. The marginal seal of Class II restorations: Flowable composite resin compared to injectable glass ionomer. J Clin Pediatr Dent 1999; 23:123-30.

[8] Unlu N, Krakaya S, Ozer F, Say EC. Reducing microleakage in composite resin restorations: An in vitro study. Eur J Prostho Rest Dent 2003; 11:171- 5 .

[9] Bayne SC, Thompson JY, Swift Jr, EJ, Stamatiades P, Wilkerson M. A characterization of first-generation flowable composites. J Am Dent Assoc 1998; 129: 567-77.

[10] Baroudi K, Silikas N, Watts DC. Edge-strength of flowable resincomposites. J Dent 2008; 36: 63-8.

[11] Miyasaka T, Okamura H. Measurement of polymerization shrinkage of composite resin using laser displacement meter. J Dent Mater 2005; $24: 385$.

[12] Miyasaka T, Yoshida T. Synthesis and some properties of novel low viscous base monomer. J Dent Mater 2000; 19: 177.

[13] Peutzfeldt A. Resin composites in dentistry: the monomer systems. Eur J Oral Sci 1997; 105: 97-116.

[14] Anseth KS, Newman SM, Bowman CN. Polymeric dental composites: properties and reaction behavior of multimethacrylate dental restorations. Adv Polym Sci 1995; 122:177-217.

[15] Braden M. The formulation of composite filling materials. Oper Dent 1978; 3: 97-102.

[16] Kalachandra S. Dimethacrylate monomers and polymers as biomaterials. Polym Sci 1997; 2:95-106.

[17] Pereira SG, Nunes TG, Kalachandra S. Low viscosity dimethacrylate comonomer compositions [Bis-GMA and CH3Bis-GMA] for novel dental composites; analysis of the network by stray-field MRI, solid state NMR and DSC \& FTIR. Biomater 2002; 23: 3799806.

[18] Peutzfeldt A. Quantity of remaining double bonds of diacetylcontaining resins. J Dent Res 1994; 73:511-5.

[19] Peutzfeldt A, Asmussen E. Influence of ketones on selected mechanical properties of resin composites. J Dent Res 1992; 71:184750 .

[20] Blalock JS, Holmes RG, Rueggeberg FA. Effect of temperature on unpolymerized composite resin film thickness. J Prosthet Dent 2006; 96: 424-32.

[21] Iovan G, Stoleriu S, Moldovanu A, Morogai S, Andrian S. SEM study of the interface between the cavity wall and composite resin in cavities filled using vibration. Int J Med Dent 2011; 1: 254-8.

[22] Olmez A, Oztas N, Bodur H. The effect of flowable resin composite on microleakage and internal voids in class II composite restorations. Oper Dent 2004; 29: 230-5.

[23] Tredwin CJ, Stokes A, Moles DR. Influence of flowable liner and margin location on microleakage of conventional and packable Class II resin composites. Oper Dent 2004; 30:32-8.

[24] Lindberg A, van Dijken JW, Horstedt P. In vivo interfacial adaptation of class II resin composite restorations with-and without a flowable resin composite liner. Clin Oral Investig 2005; 9:77-83.

[25] Loguercio AD, Zago C, Leal K, Ribeiro NR, Reis A. One-year clinical evaluation of a flowable resin liner associated with a microhybrid resin in noncarious cervical lesions. Clin Oral Investig 2005; 9:18-20. 
[26] Efes BG, Dörter C, Gömec Y, Koray F. Two-year clinical evaluation of ormocer and nanofill composite with and without a flowable liner. J Adhe Dent 2006; 8:119-26.

[27] Celik C, Ozgunaltay G, Attar N. Clinical evaluation of flowable resins in non-carious cervical lesions: two-year results. Oper Dent 2007; 32: 313-21.

[28] Sadeghi M. Influence of flowable materials on microleakage of nanofilled and hybrid Class II composite restorations with LED and QTH LCUs. Indian J Dent Res 2009; 20:159-63.

[29] Kubo S, Yokota H, Yokota H, Hayashi Y. Three-year clinical evaluation of a flowable and a hybrid resin composite in noncarious cervical lesions. J Dent 2010; 38:191-200.

[30] Gallo JR, Burgess JO, Ripps AH, et al. Three-year clinical evaluation of two flowable composites. Quintessence Int 2010; 41: 497503.

[31] Van Djken JW, Pallesen U. Clinical performance of a hybrid resin composite with and without an intermediate layer of flowable resin composite. A 7-year evaluation. Dent Mater J 2011; 27:150-6.

[32] Simi B, Suprabha BS. Evaluation of microleakage in posterior nanocomposite restorations with adhesive liners. JCD 2011; 14: 178.

[33] Bonilla ED, Stevenson RG, Caputo AA, White SN. Microleakage resistance of minimally invasive class I flowable composite restorations. Oper Dent 2012; 37: 290-8.

[34] Arslan S, Demirbuga S, Ustun Y, Dincer AN, Canakci BC, Zorba YO. The effect of a new-generation flowablecomposite resin on microleakage in Class $\mathrm{V}$ composite restorations as an intermediate layer. J Conserv Dent 2013; 16: 189-93.

[35] Pecie R, Onisor I, Krejci I, Bortolotto T. Marginal adaptation of direct class II composite restorations with different cavity liners. Oper Dent 2013; 38: 210-20.

[36] Pereira SG, Osorio R, Toledano M, Nunes TG. Evaluation of two Bis-GMA analogues as potential monomer diluents to improve the mechanical properties of light polymerized composite resins. Dent Mater 2005; 21: 823-30.

[37] Okamura H, Miyasaka T, Hagiwara T. Development of dental composite resin utilizing low-shrinking and low-viscous monomers. Den Mater J 2006; 25: 437-44.

[38] Charton C, Falk V, Marchal P, Pla F, Colon P. Influence of Tg, viscosity and chemical structure of monomers on shrinkage stress in light-cured dimethacrylate-based dental resins. Dent Mater J 2007; 23:1447-59.

[39] Prakki A, Cilli R, Mondelli RFL, Kalachandra S. In vitro wear, surface roughness and hardness of propanal-containing and diacetyl-containing novel composites and copolymers based on bisGMA analogs. Dent Mater 2008; 24: 410- 17.

[40] Prakki A, Pereira PNR, Kalachandra S. Effect of propionaldehyde and 2,3-butanedione additives on the mechanical properties of BisGMA analog-based composites. Dent Mater 2009; 25: 26-32.

[41] Denis AB, Plepis AMG, Martins VDCA, Pereira JC, Cilli R, Prakki A. Properties of experimental resins based on synthesized propoxylated bis-GMA with different propionaldehyde ratios. Mater Res 2012; 15: 397-402.
[42] Prakki A, Cilli R, Vieira IM, Dudumas K, Pereira JC. Water sorption of $\mathrm{CH} 3$-and $\mathrm{CF} 3-\mathrm{Bis}-\mathrm{GMA}$ based resins with additives. J Applied Oral Sci 2012; 20: 472-7.

[43] Aksu MN, Linger J. Effect of pre-heating composite on microleakage in Class II restorations. J Dent Res 2004:83.

[44] Daronch M, Rueggeberg FA, De Goes MF. Monomer Conversion of Pre-heated Composite. J Dent Res 2005; 84: 663-7.

[45] Wagner WC, Asku MN, Neme AL, Linger J B, Pink FE, Walker S. Effect of pre-heating resin composite on restoration microleakage. Oper Dent 2008; 25: 3087-97.

[46] Walter R, Swift EJ Jr, Sheikh H, Ferracane JL. Effects of temperature on composite resin shrinkage. Quintessence Int 2009; 40(10): 843-7.

[47] Lohbauer U, Zinelis S, Rahiotis C, Petschelt A, Eliades G. The effect of resin composite pre-heating on monomer conversion and polymerization shrinkage. Dent Mater 2009; 25: 514-9.

[48] Lucey S, Lynch CD, Ray NJ, Burke FM, Hannigan A. Effect of pre-heating on the viscosity and microhardness of a resin composite. J Oral Rehabil 2010; 37(4): 278-82.

[49] Fróes-Salgado NR, Silva LM, Kawano Y, Francci C, Reis A, Loguercio AD. Composite pre-heating: effects on marginal adaptation, degree of conversion and mechanical properties. Dent Mater 2010; 26: 908-14.

[50] Tantbirojn D, Chongvisal S, Augustson DG, Versluis A. Hardness and postgel shrinkage of preheated composites. Quintessence Int 2011; 42(3): 51-9.

[51] Deb S, Di Silvio L, Mackler HE, Millar BJ. Pre-warming of dental composites. Dent Mater 2011; 27: 51-9.

[52] Dos Santos RA, Lima AF, Soares GP, et al. Effect of preheating resin composite and light-curing units on the microleakage of Class II restorations submitted to thermocycling. Oper Dent 2011;36: 605 .

[53] Nada K, El-Mowafy O. Effect of precuring warming on mechanical properties of restorative composites. Int J Dent 2011; 2011: 536212.

[54] Karaarslan ES, Usumez A, Ozturk B, Cebe MA. Effect of cavity preparation techniques and different preheating procedures on microleakage of class V resin restorations. Eur J Dent 2012; 6: 87-94.

[55] Yapp R, Powers JM. Depth of cure of several composite restorative materials. Dent Advis Res Report 2011; 33:1.

[56] Eunice C, Margarida A, João CL, et al. $99 \mathrm{~m}$ Tc in the evaluation of microleakage of composite resin restorations with Sonic fill. An in vitro experimental model. Open J Stomatol 2012; 2: 340-7.

[57] Ilie N, Bucuta S, Draenert M. Bulk-fill resin-based composites: an in vitro assessment of their mechanical performance. Oper Dent 2013; 38: 618-25.

[58] Poggio C, Chiesa M, Scribante A, Mekler J, Colombo M. Microleakage in Class II composite restorations with margins below the CEJ: In vitro evaluation of different restorative techniques. Med Oral Patol Oral Cir Bucal 2013; 18: 793-98.

[59] Alrahlah A, Silikas N, Watts DC. Post-cure depth of cure of bulk fills dental resin-composites. Dent Mater 2014; 30: 149-54.

(C) Baroudi and Mahmoud; Licensee Bentham Open.

This is an open access article licensed under the terms of the Creative Commons Attribution Non-Commercial License (http://creativecommons.org/licenses/by-nc/3.0/) which permits unrestricted, non-commercial use, distribution and reproduction in any medium, provided the work is properly cited. 